\title{
Subadditive responses to extremely short blue and green pulsed light on visual evoked potentials, pupillary constriction and electroretinograms
}

\author{
Soomin Lee ${ }^{1 *}$ D, Yuria Uchiyama², Yoshihiro Shimomura ${ }^{2}$ and Tetsuo Katsuura ${ }^{2}$
}

\begin{abstract}
Background: The simultaneous exposure to blue and green light was reported to result in less melatonin suppression than monochromatic exposure to blue or green light. Here, we conducted an experiment using extremely short blue- and green-pulsed light to examine their visual and nonvisual effects on visual evoked potentials (VEPs), pupillary constriction, electroretinograms (ERGs), and subjective evaluations.

Methods: Twelve adult male subjects were exposed to three light conditions: blue-pulsed light (2.5-ms pulse width), green-pulsed light (2.5-ms pulse width), and simultaneous blue- and green-pulsed light with white background light. We measured the subject's pupil diameter three times in each condition. Then, after 10 min of rest, the subject was exposed to the same three light conditions. We measured the averaged ERG and VEP during 210 pulsed-light exposures in each condition. We also determined subjective evaluations using a visual analog scale (VAS) method.

Results: The pupillary constriction during the simultaneous exposure to blue- and green-pulsed light was significantly lower than that during the blue-pulsed light exposure despite the double irradiance intensity of the combination. We also found that the b/|a| wave of the ERGs during the simultaneous exposure to blue- and green-pulsed light was lower than that during the blue-pulsed light exposure. We confirmed the subadditive response to pulsed light on pupillary constriction and ERG. However, the P100 of the VEPs during the blue-pulsed light were smaller than those during the simultaneous blue- and green-pulsed light and green-pulsed light, indicating that the P100 amplitude might depend on the luminance of light.

Conclusions: Our findings demonstrated the effect of the subadditive response to extremely short pulsed light on pupillary constriction and ERG responses. The effects on ipRGCs by the blue-pulsed light exposure are apparently reduced by the simultaneous irradiation of green light. The blue versus yellow (b/y) bipolar cells in the retina might be responsible for this phenomenon.
\end{abstract}

\section{Introduction}

Intrinsically photosensitive retinal ganglion cells (ipRGCs) affect the suprachiasmatic nucleus and act as the primary photoreceptor for nonvisual effects such as the suppression of pineal melatonin synthesis [1-3], circadian photoentrainment [4-6], and other behavioral and physiological functions [5-8]. The discovery of ipRGCs that express the

\footnotetext{
* Correspondence: yisoomin@chiba-u.jp

${ }^{1}$ Center for Environment, Health and Sciences, Chiba University, 6-2-1

Kashiwanoha, Kashiwa, Chiba 277-0882, Japan

Full list of author information is available at the end of the article
}

photopigment melanopsin and send retinal information to the brain centers for controlling pupil size has led to a better understanding of retinal mechanisms contributing to pupil responses $[4,7,9-20]$. The ipRGCs respond to shortwavelength light of around $480 \mathrm{~nm}$ [21-23], and the contribution of ipRGCs to the pupillary light response was greater at a higher irradiance, with the role of the rods being more dominant at a lower irradiance level $[4,15,17,24]$. Besides, we found that the pupillary response under the extremely short (pulse width $100 \mu \mathrm{s})$ but higher irradiance $(11.2 \mu \mathrm{W} /$ $\mathrm{cm}^{2}$ or $13.4 \log$ photons $/ \mathrm{cm}^{2} / \mathrm{s}$ ) blue-pulsed light was 
significantly greater than that under the steady blue light $\left(1.4 \mu \mathrm{W} / \mathrm{cm}^{2}\right.$ or $12.5 \mathrm{log}$ photons $\left./ \mathrm{cm}^{2} / \mathrm{s}\right)$ which had equal blue light components (the products of irradiance and duration) [12]. We assumed that the pulsed light of strong irradiance might induce significantly greater pupillary response [25].

By the way, Figueiro et al. [26] found that simultaneous exposure to blue and green light resulted in less melatonin suppression than monochromatic light exposure to blue or green light. This effect was named the "subadditive response" to light [26]. We defined the "subadditive response to light" as the effect of simultaneous exposure to several color lights was smaller than that of monochromatic light exposure. In our previous study, we observed that pupillary constriction during the simultaneous exposure to pulses of blue and green light was smaller than during exposure to a pulse of blue light despite the double irradiance intensity of the combination [27]. Subadditive responses were also found in other studies of monochromatic and polychromatic light on melatonin suppression [28-30]. By contrast, Papamichael et al. [31] examined the effect of the concurrent administration of blue and red monochromatic light on acute melatonin suppression and subjective mood and alertness responses in humans. They reported that the primary determinant of the melatonin suppression response was the irradiance of $479 \mathrm{~nm}$ blue light, and this was unaffected by a simultaneous administration of red light [31]. In this way, a subadditive response for the spectral power distribution of the light has not yet been confirmed.

Moreover, it remains unclear whether the subadditive response affects pupillary constriction. An electroretinogram (ERG) has been used in a few studies to inspect ipRGC function [32, 33], commonly recorded by using electrodes such as a contact lens that contacted the cornea. However, these types of electrodes have the potential to cause corneal abrasions and infections of the cornea [34]. ERGs have alternatively been recorded by using skin electrodes [34-42]. These studies suggested that ERG responses of skin electrodes had a smaller amplitude but were quite similar to those of eye-contact electrodes [37, 38, 41, 42]. Recently, ERG responses have been successfully measured by using the skin electrodes with a pulse reference power line noise reduction (PURE) method $[39,40]$ to assess the retinal functions, demonstrating the utility of this approach.

Taking advantage of this recent advancement in ERG technology, this study comprehensively clarified the visual and nonvisual effects of blue and green light in order to understand the subadditive response to blue light more fully. In this study, we measured visual evoked potentials (VEPs), pupillary constriction, ERGs, and subjective evaluations in response to extremely short pulsed blue and green light.

\section{Methods}

\section{Subjects}

Twelve healthy young males (age $24 \pm 1.3$ years, body height $168.6 \pm 4.1 \mathrm{~cm}$, body weight $59.2 \pm 7.7 \mathrm{~kg}$ ) with normal color vision participated in the experiment. We confirmed that the subjects had normal color vision by administering the Farnsworth Munsell 100 Hue Test. The subjects were sufficiently informed about the experimental procedure and gave informed consent. They were not allowed to perform vigorous exercise or to consume alcoholic drinks or caffeine-containing foods before the experiment. This experiment was approved by the Ethics Committee of the Graduate School of Engineering, Chiba University (No. 26-08).

\section{Lighting condition}

Each subject was exposed simultaneously or separately to $2.5 \mathrm{~ms}$ of blue and/or green extremely short pulsed lights at $1.6 \times 10^{15}$ photons $/ \mathrm{cm}^{2} / \mathrm{s}$ or $15.2 \log$ photons/ $\mathrm{cm}^{2} / \mathrm{s}$ (Table 1) with white background light from an incandescent lamp $\left(2287 \mathrm{~K}, 30 \mathrm{~cd} / \mathrm{m}^{2}\right)$, using an integrating sphere (Takano Co., Nagano, Japan) in a booth $(1420 \times 510 \times 1750 \mathrm{~mm})$. The spectral distribution for the green and blue light-emitting diodes (LEDs) and the incandescent lamp was measured at each subject's eye level using a spectroradiometer (CL-500A, Konica Minolta Optics Co., Tokyo). The wavelength of peak emission from the blue LED was $464 \mathrm{~nm}$ and that from the green LED was $526 \mathrm{~nm}$ (Fig. 1). The full width at half maximum of these LEDs was $22 \mathrm{~nm}$ and $31 \mathrm{~nm}$, respectively (Table 1 ). The experiment was conducted in a climatic chamber (TBR-6HA4G2C; Espec Corp., Osaka, Japan) in which the air temperature and relative humidity were set at $25^{\circ} \mathrm{C}$ and $50 \%$, respectively.

\section{Procedure and measurements}

The subject sat on a chair with his eyes facing the integrating sphere (Fig. 2). Blue and green LEDs and an

Table 1 Characteristics of the light conditions

\begin{tabular}{llll}
\hline Light condition & Blue & Green & Blue + Green \\
\hline Peak wavelength $(\mathrm{nm})$ & 464 & 526 & - \\
FWHM $(\mathrm{nm})$ & 22 & 31 & - \\
Irradiance $\left(\mu \mathrm{W} / \mathrm{cm}^{2}\right)$ & 686 & 607 & 1294 \\
Photon density $\left(10^{15}\right.$ photons $\left./ \mathrm{cm}^{2} / \mathrm{s}\right)$ & 1.61 & 1.62 & 3.24 \\
Photon density $\left(\right.$ log photons $\left./ \mathrm{cm}^{2} / \mathrm{s}\right)$ & 15.2 & 15.2 & 15.5 \\
Photopic illuminance $(\mathrm{Ix})$ & 439 & 3281 & 3734 \\
Scotopic illuminance $(\mathrm{x})$ & 7388 & 7836 & 15,204 \\
$\begin{array}{l}\text { Melanopsin-stimulating irradiance } \\
\left(\mu \mathrm{W} / \mathrm{cm}^{2}\right)\end{array}$ & 526.1 & 343.8 & 868.6 \\
$\begin{array}{l}\text { Melanopsin-stimulating photon density } \\
\left(10^{14} \text { photons/cm } / \mathrm{s}\right)\end{array}$ & 13.0 & 8.5 & 21.5 \\
\hline
\end{tabular}

FWHM full width at half maximum 


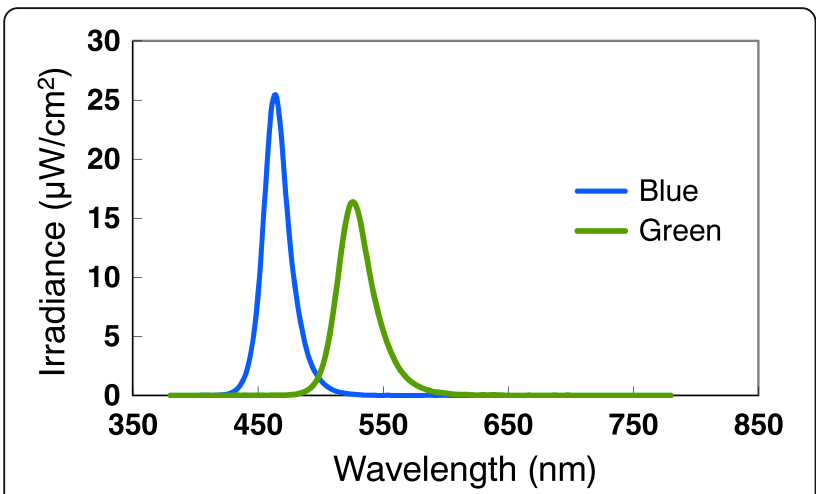

Fig. 1 Spectral irradiance of light

incandescent lamp were arrayed in the integrating sphere. After $10 \mathrm{~min}$ of base light exposure $(2287 \mathrm{~K}$, $30 \mathrm{~cd} / \mathrm{m}^{2}$ ), the subject was exposed to three pulsed lights of blue (Blue), green (Green), or simultaneous blue and green (Blue + Green) light every $10 \mathrm{~s}$ with a white background light for measuring the pupil diameter (EMR-8B, nac Image Technology, Tokyo, Japan). From the measurement of the pupil diameter (PD), we calculated the pupillary constriction ratio (\% pupillary constriction) as follows: \% pupillary constriction $=[$ (baseline PD - minimum PD after light exposure)/baseline PD] $\times 100$, and we defined the time to $75 \%$ recovery of the pupil diameter to the baseline as the recovery time.

Next, after 10 min of rest in the baseline light condition, the subject's left eye was exposed to the same three light conditions at random intervals (1.5-2.5 s) during $90 \mathrm{~min}$. We measured the averaged ERG and VEP during 210 pulsed-light exposures in each condition. We

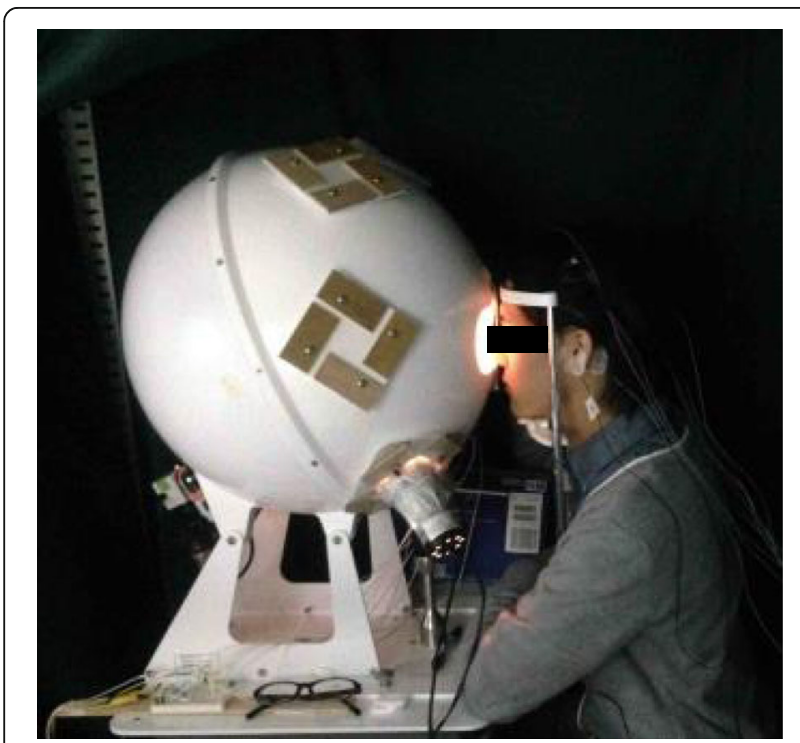

Fig. 2 Integrating sphere and a subject also determined subjective evaluations of "bluish" and "greenish" using a visual analog scale (VAS) method after each condition (Fig. 3).

We obtained averaged ERGs using an evoked response recorder (PuREC, Mayo Co., Aichi, Japan) with a pulse reference power line noise reduction (PURE) method $[39,40]$ and skin electrodes from 90 artifact-free ERG signals. The active skin electrode was placed on the orbital rim $7 \mathrm{~mm}$ from the margin of the lower eyelid of the left eye, and the reference electrode was placed on the same position on the right eye. The earth electrode was attached to the left earlobe. ERG signals were digitized at $1250 \mathrm{~Hz}$ and amplified with a digital band-pass filter of $0.3-200 \mathrm{~Hz}$. From the averaged ERG, we analyzed the amplitude of a wave, b wave, and photopic negative responses (PhNRs) (Fig. 4). The a wave amplitude was calculated as the maximum value of $10-50 \mathrm{~ms}$ after the light exposure minus the baseline average. The b wave amplitude was measured from trough of the a wave to the peak of the b wave located in 20-60 ms after the light exposure. The $\mathrm{b} /|\mathrm{a}|$ was obtained as the $\mathrm{b}$ wave amplitude divided by the absolute value of the a wave $(|\mathrm{a}|)$. The PhNRmax was then calculated as the maximum negative value of 40-200 ms after the light exposure minus the baseline average.

VEP waveforms were averaged from at least 180 artifact-free electroencephalogram (EEG) recordings at $\mathrm{Fz}$, $\mathrm{C} 3, \mathrm{Cz}, \mathrm{C} 4, \mathrm{O} 1$, and $\mathrm{O} 2$ electrode sites. EEG signals were digitized at $1000 \mathrm{~Hz}$ and amplified with digital band-pass filter of $1.0-100 \mathrm{~Hz}$ (Biopac Systems, Goleta, CA, USA).

The order of the three light conditions was counterbalanced among the subjects.

\section{Statistical analysis}

We used a one-way repeated measures analysis of variance (ANOVA) (PASW Statistic 18; Ver. 18.0J, IBM, Armonk, NY, USA) to evaluate the effects of the light factor except in the VEPs. In the VEPs, a two-way repeated-measures ANOVA (light factor $\times$ region factor) was conducted. When any significant effect was found, multiple comparisons of the light condition were performed by the Bonferroni method. Probability $(p)$ values $<0.05$ were accepted as significant.

\section{Results}

Two-way repeated measures ANOVA on P100 amplitude of VEPs revealed that the main effects of the light condition and the electrode site were significant, and the interaction effect was also significant. Therefore, a one-way repeated measures ANOVA was applied to evaluate the effects of the light condition on the P100 amplitude at each region of electrode sites. We found that the main effects of light on the P100 amplitude at the $\mathrm{Fz}, \mathrm{C} 3, \mathrm{Cz}$, and $\mathrm{C} 4$ electrode sites were significant (all $p<0.01$ ). Multiple 


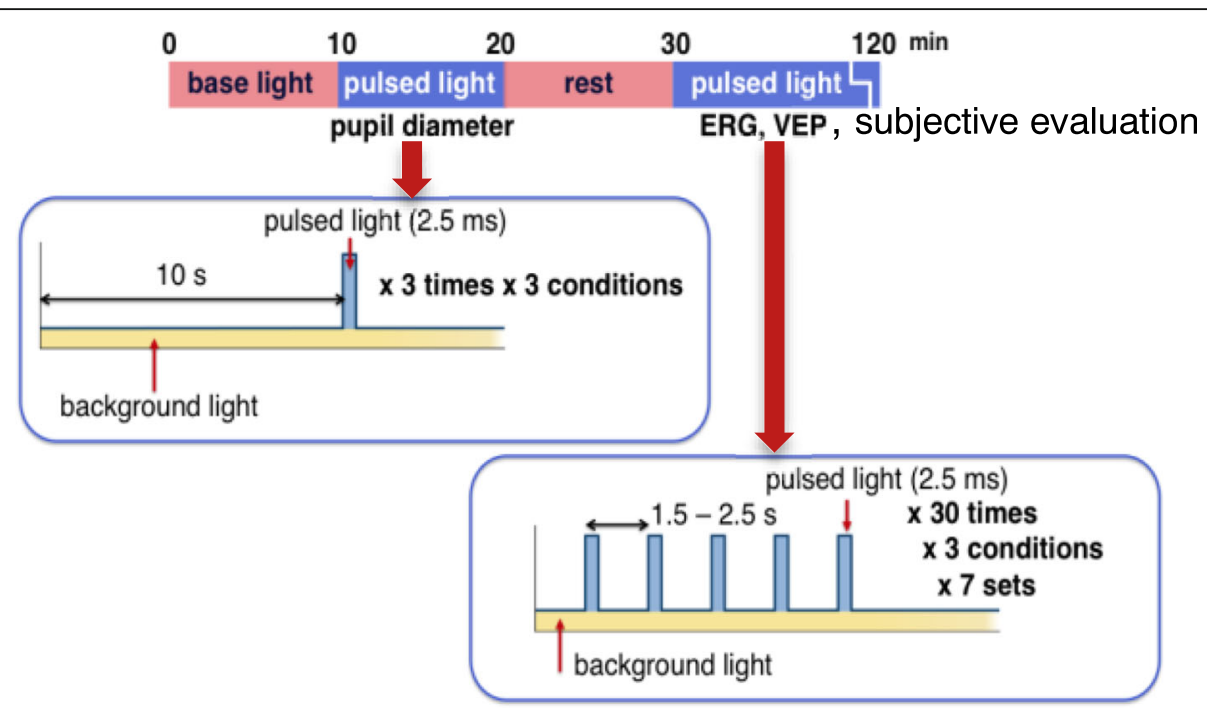

Fig. 3 The procedure of the experiment

comparisons using the Bonferroni procedure found that the P100 amplitudes at the $\mathrm{Fz}, \mathrm{C} 3$, and $\mathrm{Cz}$ electrode sites during the Blue condition were significantly smaller than those during the Blue + Green condition, and those at the same electrode sites during the Blue condition were also significantly smaller than those during Green condition (Fig. 5a-c; $p<0.05$ or $p<0.01$ ). There were no significant main effects of the light condition on the P100 amplitude at the $\mathrm{Pz}, \mathrm{O} 1$, and $\mathrm{O} 2$ sites.

We found that the main effects of light on the percentage of pupillary constriction and the recovery time were significant (both $p<0.01$ ). Multiple comparisons using the Bonferroni procedure revealed that the percentage of pupillary constriction during the Blue + Green condition was significantly lower than that during the Blue condition (Fig. 6a; $p<0.01$ ), and the recovery time during the Blue + Green condition was significantly shorter than that during the Blue condition (Fig. 6b; $p<0.05$ ) despite the double irradiance intensity of the combination.

Figure 7 shows the results of the ERG components (a wave, $\mathrm{b} /|\mathrm{a}|$, and $\mathrm{PhNRmax}$ ) during the three light conditions. One-way repeated measures ANOVA on a wave, b/

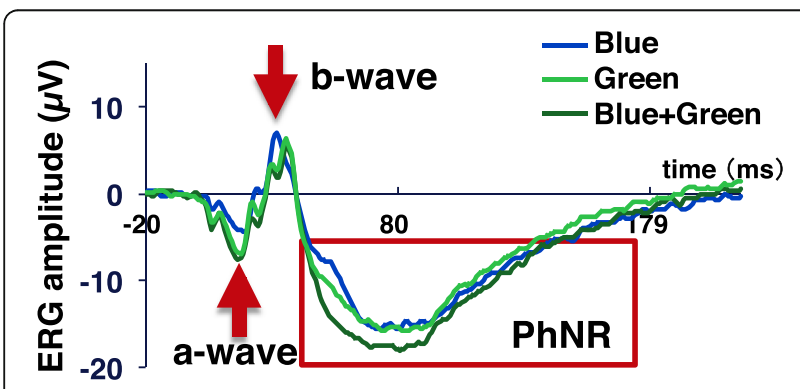

Fig. 4 Grand average of ERG $|\mathrm{a}|$, and PhNRmax showed a significant (all $p<0.01$ ) main effect of light. The a wave during the Blue condition was significantly smaller than that during the Blue + Green condition (Fig. 7a; $p<0.01$ ). The $\mathrm{b} /|\mathrm{a}|$ of the ERG during the Blue + Green condition resulted in a significantly smaller ratio than that during the Blue or Green condition (Fig. 7b; $p<0.01$ and $p<0.05$, respectively). In addition, the PhNRmax during the Blue + Green condition was significantly larger than that during the Blue or Green condition (Fig. 7c; $p<0.05$ and $p<0.01$, respectively).

There were no significant differences in the results of the subjective evaluations of "bluish" and "greenish" scores between the Blue and the Blue + Green condition (Fig. 8).

\section{Discussion}

Our findings demonstrated a subadditive response to extremely short pulsed light in terms of pupillary constriction and ERG responses, but no subadditive response was evident in the VEP results. We discussed in each of these results in turn below and interpreted what they might mean in terms of the cell types in the retina that might be responsible for this phenomenon.

VEPs convey the visual, but not the nonvisual, response to blue and green light

The P100 amplitude of the VEPs at the Fz, Cz, and C3 electrode sites during the Blue + Green condition was significantly higher than that during the Blue condition, but there were no significant differences in the P100 amplitudes of the VEPs at these sites during the Green and Blue + Green conditions. There was no subadditive response in the VEPs. Paulus et al. [43] reported that the P100 reflected the external stimuli volume response and increased with the increase in luminance. In the present study, the luminance 

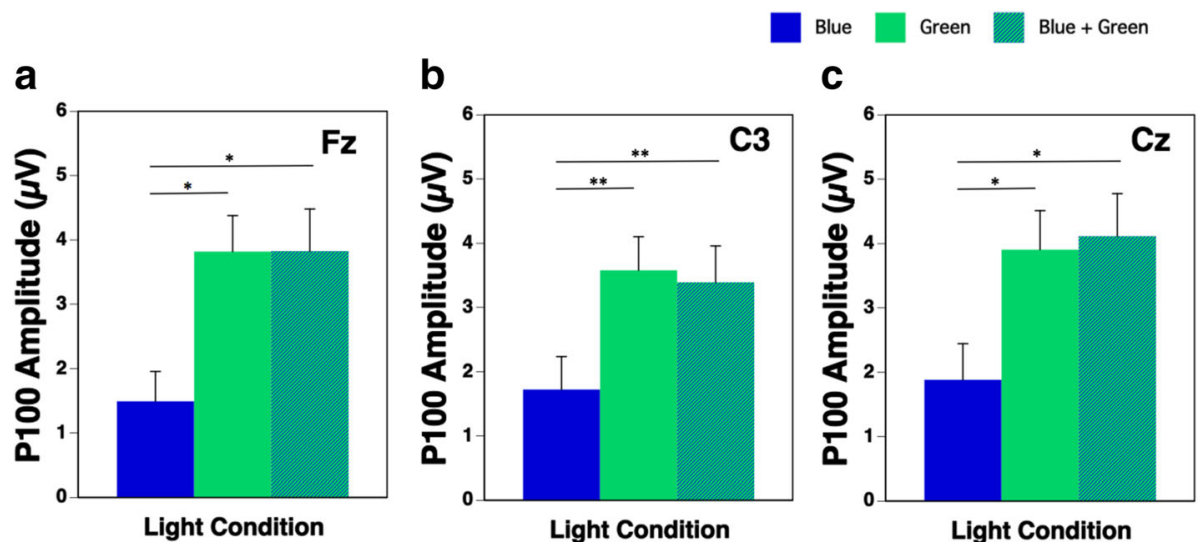

Fig. 5 P100 amplitude at Fz (a), C3 (b), and Cz (c) during the three light conditions (Blue: blue-pulsed light; green: green-pulsed light; Blue + Green: simultaneous blue- and green-pulsed light; ${ }^{*} p<0.05 ;{ }^{* *} p<0.01$ )

differed among the three lighting conditions (Blue $245 \mathrm{~cd} /$ $\mathrm{m}^{2}$, Green $2043 \mathrm{~cd} / \mathrm{m}^{2}$, and Blue + Green $2250 \mathrm{~cd} / \mathrm{m}^{2}$ ) because the photon density of the blue and green light was standardized as $1.6 \times 10^{15}$ photons $/ \mathrm{cm}^{2} / \mathrm{s}$. We thus presumed that the P100 response did not reflect the nonvisual system but rather reflected the visual system including the luminance. There was no subadditive response in the VEPs. This result suggested that the activation of the brain depended on the luminance and reflects the brightnes$\mathrm{s}-$ i.e., the visual system was activated-at around $100 \mathrm{~ms}$ after the light stimuli presentation.

\section{Pupillary constriction shows a subadditive response to blue and green light}

We observed that the percentage of pupillary constriction during the Blue condition was greater than that during the Green condition. This result was in agreement with the previous studies $[7,27]$. The recovery time during the Blue condition was longer than that during the Green condition. Other studies have demonstrated that the ipRGCs respond to short-wavelength light of around $480 \mathrm{~nm}$ [21-23]. The ipRGCs have been reported to contribute to the pupillary response to light in mice at an irradiance level greater than about $13 \log$ photons $/ \mathrm{cm}^{2} / \mathrm{s}$ of $470 \mathrm{~nm}$ light at the eye level [17]. In the present study, the irradiance intensity of Blue was $15.2 \log$ photons $/ \mathrm{cm}^{2} / \mathrm{s}$, which was much higher than the threshold intensity for activation of ipRGCs. The ipRGCs were shown to contribute to pupillary constriction as a nonvisual effect [15], and they reacted slowly and longwise after the light stimulation [22]. In fact, the result of the pupillary constriction and the recovery time did not reflect the luminance difference among the three lighting conditions. Therefore, we propose that the increase in pupillary constriction and the delay in recovery time during the Blue

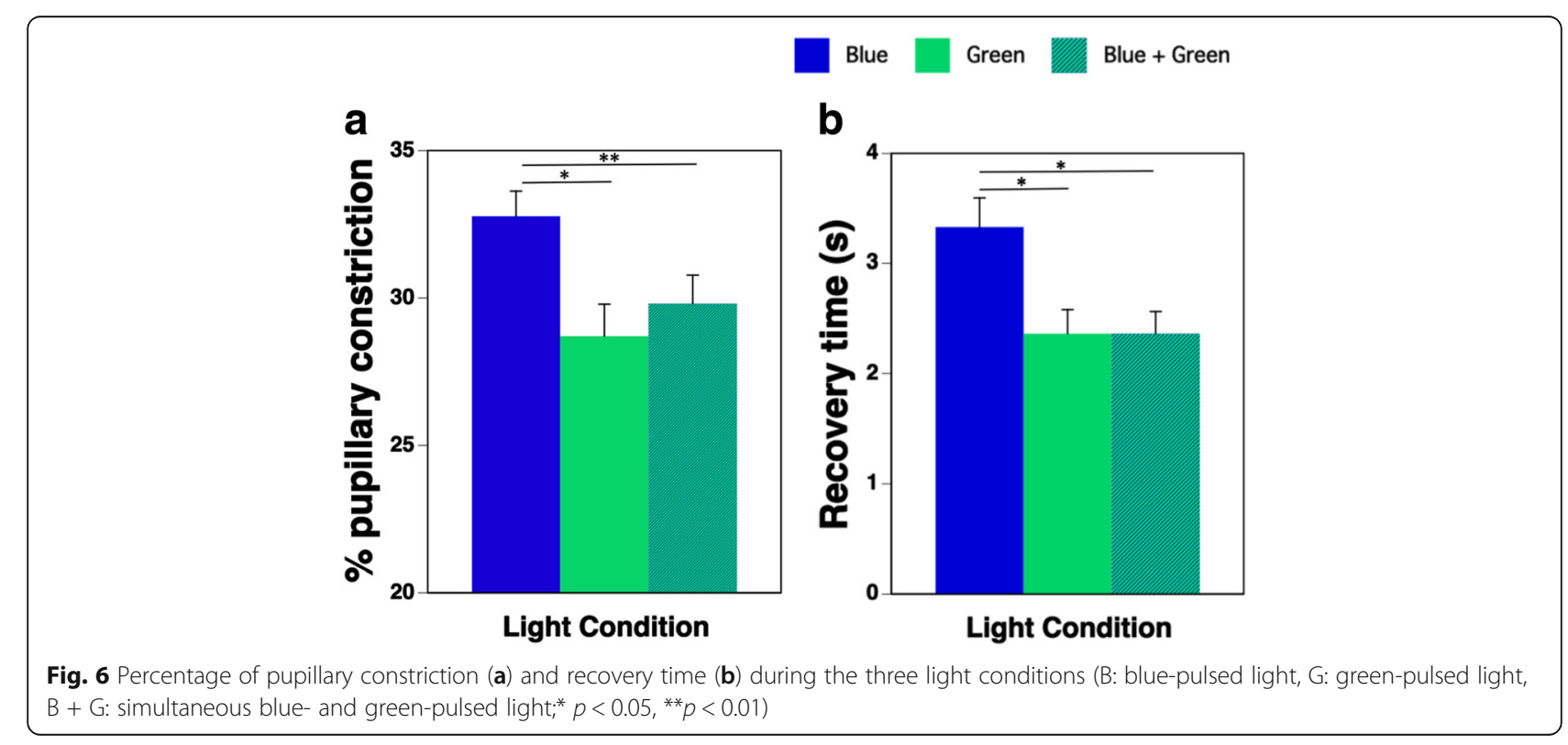



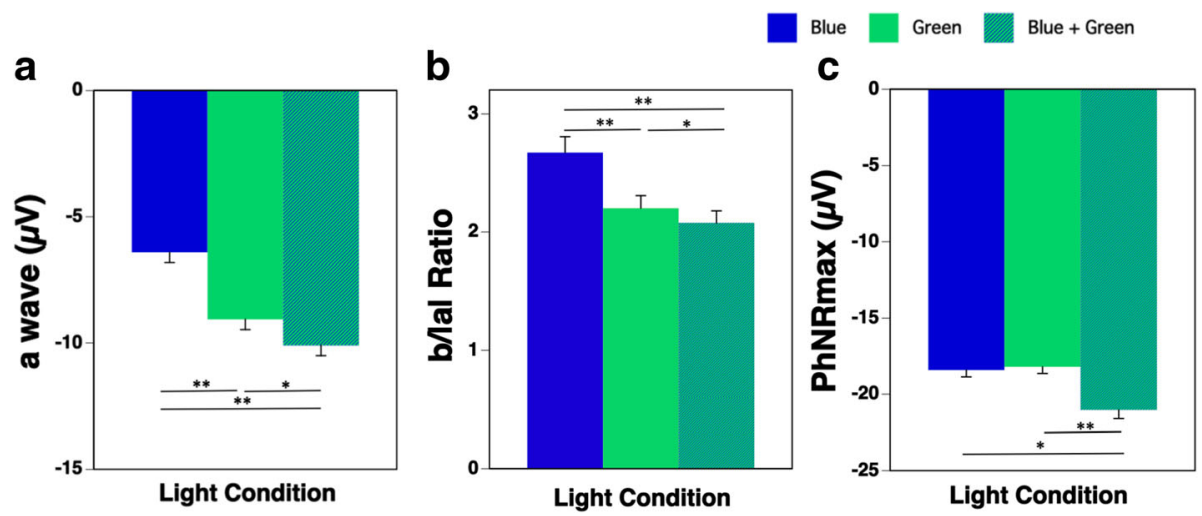

Fig. 7 ERG components of a wave (a), b/|a| ratio (b), and PhNRmax (c) during the three light conditions (Blue: blue-pulsed light; Green: green-pulsed light; Blue + Green: simultaneous blue- and green-pulsed light; $\left.{ }^{*} p<0.05 ;{ }^{* *} p<0.01\right)$

condition reflect the ipRGCs' action. The findings of the current experiment show that the nonvisual effect of blue light exposure was prominent in pupillary constriction and the recovery time.

The most important finding in the present study was that the percentage of pupillary constriction in response to the Blue + Green condition was more inhibited and shortened compared to that during the Blue condition, despite the double irradiance intensity of the combination. This showed an apparent subadditive response to pulsed light.

The information of the light wavelength is processed by bipolar cells, horizontal cells, and amacrine cells after being outputted from three types of cone [44], and this information is converted into red/green $(\mathrm{r} / \mathrm{g})$, blue/yellow (b/y), and brightness information in the ganglion cells, before traveling on to the visual cortex via the optic nerves. The spectral opponent b/y bipolar cells have been hypothesized to provide direct input to the ipRGCs [26]. The ipRGCs show an unusual "color-opponent" receptive field in which an S-cone-mediated OFF response is antagonistic to an $(\mathrm{L}+\mathrm{M})$ cone-mediated $\mathrm{ON}$ response in the in vitro primate retina [22], and an S-cone-mediated ON response is opposed to an $(\mathrm{L}+\mathrm{M})$ cone-mediated OFF response [45]. Therefore, the responses of ipRGCs activated by $\mathrm{S}$-cones might be reduced by inhibition from $(\mathrm{L}+\mathrm{M})$ cones on simultaneous exposure to blue and green light.

\section{A subadditive response to blue and green light is evident in the ERG}

To assess the retinal functions more directly, we also measured ERG in the present study. ERG response has commonly several components of $\mathrm{a}$ and $\mathrm{b}$ waves $[46,47]$. Although their precise origin and meaning remain to be elucidated [32], previous studies indicated that the a wave shows an initial response after light exposure and reflects the response of photoreceptors, especially cone cells [48, 49], and pharmacological studies revealed that the b wave reflects ON bipolar activities in the retina $[46,47]$.
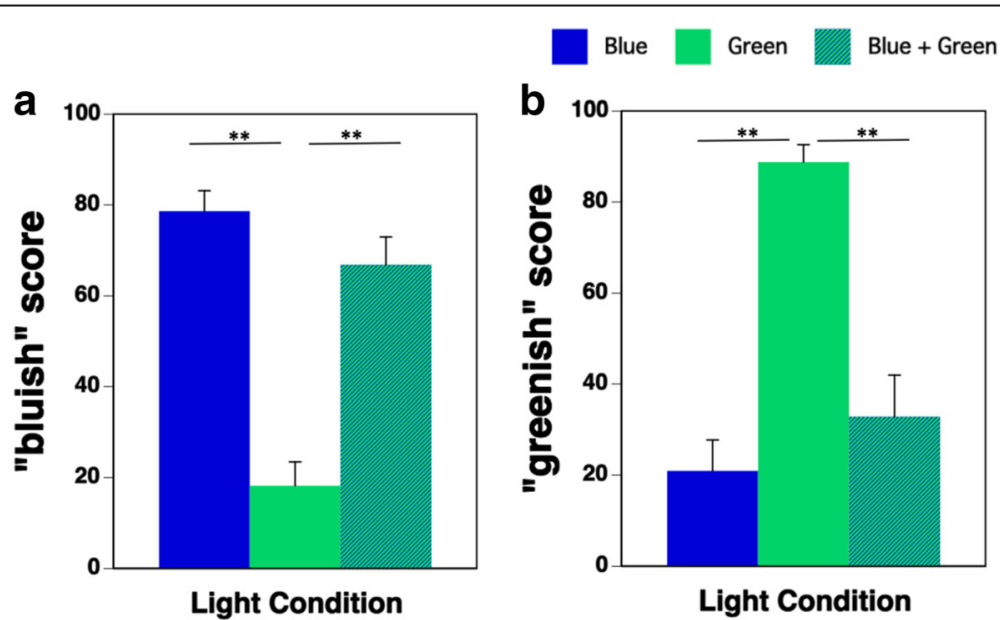

Fig. 8 "Bluish" (a) and "greenish" (b) scores during the three light conditions (Blue: blue-pulsed light; Green: green-pulsed light; Blue + Green: simultaneous blue- and green-pulsed light; ${ }^{* *} p<0.01$ ) 
The a wave amplitude of the ERGs during the present Blue + Green condition was significantly larger than that during the Blue and Green condition, respectively. In addition, the a wave amplitude during the Green condition was greater than that during the Blue condition. There was no subadditive response in the a wave component of the ERGs. This result might be related to the difference in the luminance (blue $245 \mathrm{~cd} / \mathrm{m}^{2}$, green $2043 \mathrm{~cd} /$ $\mathrm{m}^{2}$ ) even though the photon density of the Blue condition was equal to that of the Green condition, because the a wave mainly reflects the response of cone cells $[48,49]$.

The $\mathrm{b}$ wave amplitude depends on the a wave and the integrity of signal transmission within the retina; therefore, the $b /|a|$ depends only on retinal function [50]. The $\mathrm{b} /|\mathrm{a}|$ values during the Blue and Green conditions were larger than those in the Blue + Green condition. These results confirmed that the subadditive response occurred in the retina. Thus, we speculate that in the present study, the subadditive response occurred along the process of the transmission of the information from bipolar cells to ipRGCs within the retina.

The output from bipolar cells is then transmitted to ipRGCs, and the result of the photoreceptor output appears in a slow negative potential (PhNRs) following the $\mathrm{a}$ and $\mathrm{b}$ waves of photopic ERG, as was found in animal studies [51-54] and in a human study [42]. The PhNR has been reported to originate from the spiking activity of the ipRGCs and their axons, with contributions from amacrine and surrounding glial cells in the retina [5154]. We confirmed that the PhNRmax during the Blue + Green condition was significantly greater than that during the Blue and Green conditions; therefore, it was not difficult to estimate the additive response in the PhNR.

There were no significant differences in the subjective evaluations of the "bluish" and "greenish" scores between the Blue and Blue + Green condition. This showed that the effect of the simultaneous irradiation of Green on the perception of color was very small.

\section{Conclusions}

We examined VEPs, pupillary constriction, and ERGs during separate and simultaneous exposure to extremely short pulses of blue and green light. We found that the P100 amplitude of the VEP during the simultaneous exposure to pulses of blue and green light was significantly higher than that during the blue light exposure. We concluded that the P100 response did not reflect the nonvisual system but rather reflected the visual system including the luminance. However, pupillary constriction during exposure to a blue light was significantly greater than during exposure to a green light. Interestingly, pupillary constriction during the simultaneous exposure to blue and green light was smaller than during exposure to a blue light despite the double irradiance intensity of the combination. In addition, the $\mathrm{b} /|\mathrm{a}|$ values of ERG during the blue and green light exposures were larger than those in the Blue + Green exposure. Our findings demonstrated the effect of the subadditive response to extremely short pulsed light on pupillary constriction and the ERG as a nonvisual effect. The responses to the blue-pulsed light exposure were apparently reduced by the simultaneous irradiation of green-pulsed light. The blue versus yellow (b/y) bipolar cells in the retina might be responsible for this phenomenon.

\section{Abbreviations \\ ipRGCs: Intrinsically photosensitive retinal ganglion cells; LED: Light-emitting diode \\ Acknowledgements \\ We would like to thank all the subjects who willingly participated in this study. \\ Funding \\ This work was supported by JSPS KAKENHI grant number 26291098.}

\section{Availability of data and materials}

The datasets during the current study are available from the corresponding author on reasonable request.

\section{Authors' contributions}

SL wrote the manuscript. YU carried out this experiment. YU and SL analyzed the data. TK conceived of the study. SL, YU, YS, and TK were responsible for coordination of the study and overseeing data collection and analysis. All authors have read and approved the final the manuscript.

Ethics approval and consent to participate

Our experiment received institutional ethics approval from the Ethics

Committee of the Graduate School of Engineering at Chiba University (\#26-08),

and written informed consent was obtained from each participant.

\section{Consent for publication}

All participants gave written informed consent for publication after a complete explanation of this study.

\section{Competing interests}

The authors declare no conflict of interest associated with this manuscript.

\section{Publisher's Note}

Springer Nature remains neutral with regard to jurisdictional claims in published maps and institutional affiliations.

\section{Author details}

${ }^{1}$ Center for Environment, Health and Sciences, Chiba University, 6-2-1 Kashiwanoha, Kashiwa, Chiba 277-0882, Japan. ${ }^{2}$ Graduate School of Engineering, Chiba University, Chiba, Japan.

Received: 2 August 2017 Accepted: 14 November 2017

Published online: 17 November 2017

\section{References}

1. Brainard GC, Sliney D, Hanifin JP, Glickman G, Byrne B, Greeson JM, Jasser S, Gerner E, Rollag MD. Sensitivity of the human circadian system to shortwavelength (420-nm) light. J Biol Rhythm. 2008;23:379-86.

2. Cajochen C, Munch M, Kobialka S, Krauchi K, Steiner R, Oelhafen P, Orgul S, Wirz-Justice A. High sensitivity of human melatonin, alertness, thermoregulation, and heart rate to short wavelength light. J Clin Endocrinol Metab. 2005;90:1311-6.

3. Kozaki T, Kubokawa A, Taketomi R, Hatae K. Effects of day-time exposure to different light intensities on light-induced melatonin suppression at night. J Physiol Anthropol. 2015;34:27. 
4. Güler AD, Ecker JL, Lall GS, Haq S, Altimus CM, Liao HW, Barnard AR, Cahill $\mathrm{H}$, Badea TC, Zhao H, et al. Melanopsin cells are the principal conduits for rod-cone input to non-image-forming vision. Nature. 2008;453:102-5.

5. Panda S, Sato TK, Castrucci AM, Rollag MD, DeGrip WJ, Hogenesch JB, Provencio I, Kay SA. Melanopsin (Opn4) requirement for normal lightinduced circadian phase shifting. Science. 2002;298:2213-6.

6. Ruby NF, Brennan TJ, Xie X, Cao V, Franken P, Heller HC, O'Hara BF. Role of melanopsin in circadian responses to light. Science. 2002;298:2211-3.

7. Daneault V, Vandewalle G, Hebert M, Teikari P, Mure LS, Doyon J, Gronfier C, Cooper HM, Dumont M, Carrier J. Does pupil constriction under blue and green monochromatic light exposure change with age? J Biol Rhythm. 2012;27:257-64.

8. Yuda E, Ogasawara H, Yoshida Y, Hayano J. Enhancement of autonomic and psychomotor arousal by exposures to blue wavelength light: importance of both absolute and relative contents of melanopic component. J Physiol Anthropol. 2017;36:13.

9. Gamlin PD, McDougal DH, Pokorny J, Smith VC, Yau KW, Dacey DM. Human and macaque pupil responses driven by melanopsin-containing retinal ganglion cells. Vis Res. 2007;47:946-54.

10. Herbst K, Sander B, Lund-Andersen H, Broendsted AE, Kessel L, Hansen MS, Kawasaki A. Intrinsically photosensitive retinal ganglion cell function in relation to age: a pupillometric study in humans with special reference to the age-related optic properties of the lens. BMC Ophthalmol. 2012;12:4.

11. Kardon R, Anderson SC, Damarjian TG, Grace EM, Stone E, Kawasaki A. Chromatic pupil responses: preferential activation of the melanopsinmediated versus outer photoreceptor-mediated pupil light reflex. Ophthalmology. 2009;116:1564-73.

12. Katsuura T, Ochiai Y, Senoo T, Lee S, Takahashi Y, Shimomura Y. Effects of blue pulsed light on human physiological functions and subjective evaluation. J Physiol Anthropol. 2012;31:23.

13. Lall GS, Revell VL, Momiji H, Al Enezi J, Altimus CM, Guler AD, Aguilar C, Cameron MA, Allender S, Hankins MW, et al. Distinct contributions of rod, cone, and melanopsin photoreceptors to encoding irradiance. Neuron. 2010;66:417-28.

14. Lee SI, Hida A, Tsujimura S, Morita T, Mishima K, Higuchi S. Association between melanopsin gene polymorphism (I394T) and pupillary light reflex is dependent on light wavelength. J Physiol Anthropol. 2013;32:16.

15. Lucas RJ, Hattar S, Takao M, Berson DM, Foster RG, Yau KW. Diminished pupillary light reflex at high irradiances in melanopsin-knockout mice. Science. 2003;299:245-7.

16. Mure LS, Cornut PL, Rieux C, Drouyer E, Denis P, Gronfier C, Cooper HM. Melanopsin bistability: a fly's eye technology in the human retina. PLoS One. 2009:4:e5991.

17. Panda S, Provencio I, DC T, Pires SS, Rollag MD, Castrucci AM, Pletcher MT, Sato TK, Wiltshire T, Andahazy $M$, et al. Melanopsin is required for nonimage-forming photic responses in blind mice. Science. 2003;301:525-7.

18. Tsujimura S, Ukai K, Ohama D, Nuruki A, Yunokuchi K. Contribution of human melanopsin retinal ganglion cells to steady-state pupil responses. Proc Biol Sci. 2010;277:2485-92.

19. Vartanian GV, Zhao X, Wong KY. Using flickering light to enhance nonimageforming visual stimulation in humans. Invest Ophthalmol Vis Sci. 2015;56:4680-8.

20. Young RS, Kimura E. Pupillary correlates of light-evoked melanopsin activity in humans. Vis Res. 2008;48:862-71.

21. Berson DM, Dunn FA, Takao M. Phototransduction by retinal ganglion cells that set the circadian clock. Science. 2002;295:1070-3.

22. Dacey DM, Liao HW, Peterson BB, Robinson FR, Smith VC, Pokorny J, Yau KW, Gamlin PD. Melanopsin-expressing ganglion cells in primate retina signal colour and irradiance and project to the LGN. Nature. 2005;433:749-54

23. Do MT, Yau KW. Intrinsically photosensitive retinal ganglion cells. Physiol Rev. 2010;90:1547-81.

24. Takahashi $Y$, Katsuura T, Shimomura Y, Iwanaga K. Prediction model of lightinduced melatonin suppression. J Light Vis Env. 2011;35:123-35.

25. Dai Q, Uchiyama Y, Lee S, Shimomura Y, Katsuura T. Effect of quantity and intensity of pulsed light on human non-visual physiological responses. J Physiol Anthropol. 2017;36:22.

26. Figueiro MG, Bierman A, Rea MS. Retinal mechanisms determine the subadditive response to polychromatic light by the human circadian system. Neurosci Lett. 2008;438:242-5.

27. Lee S, Ishibashi S, Shimomura Y, Katsuura T. Effect of simultaneous exposure to extremely short pulses of blue and green light on human pupillary constriction. J Physiol Anthropol. 2016;35:20.
28. Figueiro MG, Bullough JD, Parsons RH, Rea MS. Preliminary evidence for spectral opponency in the suppression of melatonin by light in humans. Neuroreport. 2004;15:313-6.

29. Figueiro MG, Bullough JD, Parsons RH, Rea MS. Preliminary evidence for a change in spectral sensitivity of the circadian system at night. J Circadian Rhythms. 2005:3:14

30. Revell VL, Barrett DC, Schlangen LJ, Skene DJ. Predicting human nocturnal nonvisual responses to monochromatic and polychromatic light with a melanopsin photosensitivity function. Chronobiol Int. 2010;27:1762-77.

31. Papamichael C, Skene DJ, Revell VL. Human nonvisual responses to simultaneous presentation of blue and red monochromatic light. J Biol Rhythm. 2012;27:70-8.

32. Fukuda Y, Higuchi S, Yasukouchi A, Morita T. Distinct responses of cones and melanopsin-expressing retinal ganglion cells in the human electroretinogram. J Physiol Anthropol. 2012;31:20.

33. Fukuda Y, Tsujimura S, Higuchi S, Yasukouchi A, Morita T. The ERG responses to light stimuli of melanopsin-expressing retinal ganglion cells that are independent of rods and cones. Neurosci Lett. 2010;479:282-6.

34. Yamashita T, Miki A, Tabuchi A, Funada H, Kondo M. A novel method to reduce noise in electroretinography using skin electrodes: a study of noise level, intersession variability, and reproducibility. Int Ophtalmal. 2017;37(2):317-24.

35. Mustonen E, Sulg I. Electroretinography by skin electrodes and signal averaging method. Acta Ophthalmol. 1980;58:388-96.

36. Meredith SP, Reddy MA, Allen LE, Moore AT, Bradshaw K. Full-field ERG responses recorded with skin electrodes in paediatric patients with retinal dystrophy. Doc Ophthalmol. 2004;109:57-66.

37. Bradshaw K, Hansen R, Fulton A. Comparison of ERGs recorded with skin and corneal-contact electrodes in normal children and adults. Doc Ophthalmol. 2004;109:43-55.

38. Papathanasiou ES, Papacostas SS. Flash electroretinography: normative values with surface skin electrodes and no pupil dilation using a standard stimulation protocol. Doc Ophthalmol. 2008;116:61-73.

39. Toda N. A cancellation method of periodic interference in pulse-like signals using adaptive filter and its application to flash ERGs (in Japanese). Denshi Jouhou Tsuushin Gakkai Ronbunshi. 2011;J94-D:1685-95.

40. Otaka Y, Tanikawa A, Shimada Y, Ueda I, Horiguchi M. Skin electrode electroretinogram recorded with pulse reference power line noise reduction (in Japanese). Folia Japonica de ophthalmologica clinica. 2011:4:1064-7.

41. Kaida T, Matsunaga M, Hanaya J, Nakamura Y, Ohtani S, Miyata K, Kondo M. Comparison between subtraction skin electrodes and corneal-contact electrodes in flash electroretinograms (in Japanese with English abstract). Nippon Ganka Gakkai Zasshi. 2013;117:5-11.

42. Wu Z, Hadoux X, Fan Gaskin JC, Sarossy MG, Crowston JG. Measuring the photopic negative response: viability of skin electrodes and variability across disease severities in glaucoma. Transl Vis Sci Technol. 2016;5:13.

43. Paulus WM, Homberg V, Cunningham K, Halliday AM. Colour and brightness coding in the central nervous system: theoretical aspects and visual evoked potentials to homogeneous red and green stimuli. Proc R Soc Lond B Biol Sci. 1986;227:53-66.

44. Kolb H. How the retina works. Am Sci. 2003;91:28-35.

45. Dacey DM. Parallel pathways for spectral coding in primate retina. Annu Rev Neurosci. 2000;23:743-75.

46. Sieving PA, Murayama K, Naarendorp F. Push-pull model of the primate photopic electroretinogram: a role for hyperpolarizing neurons in shaping the b-wave. Vis Neurosci. 1994:11:519-32.

47. Stockton RA, Slaughter MM. B-wave of the electroretinogram. A reflection of ON bipolar cell activity. J Gen Physiol. 1989;93:101-22.

48. Friedburg C, Allen CP, Mason PJ, Lamb TD. Contribution of cone photoreceptors and post-receptoral mechanisms to the human photopic electroretinogram. J Physiol. 2004;556:819-34.

49. Hood DC, Birch DG. The A-wave of the human electroretinogram and rod receptor function. Invest Ophthalmol Vis Sci. 1990:31:2070-81.

50. Perlman I. Relationship between the amplitudes of the $b$ wave and the $a$ wave as a useful index for evaluating the electroretinogram. $\mathrm{Br} J$ Ophthalmol. 1983;67:443-8.

51. Li B, Barnes GE, Holt WF. The decline of the photopic negative response $(\mathrm{PhNR})$ in the rat after optic nerve transection. Doc Ophthalmol. 2005;111:23-31.

52. Machida S, Raz-Prag D, Fariss RN, Sieving PA, Bush RA. Photopic ERG negative response from amacrine cell signaling in RCS rat retinal degeneration. Invest Ophthalmol Vis Sci. 2008;49:442-52. 
53. Rangaswamy NV, Frishman L, Dorotheo EU, Schiffman JS, Bahrani HM, Tang RA. Photopic ERGs in patients with optic neuropathies: comparison with primate ERGs after pharmacologic blockade of inner retina. Invest Ophthalmol Vis Sci. 2004:45:3827-37.

54. Viswanathan S, Frishman LJ, Robson JG, Harwerth RS, Smith EL 3rd. The photopic negative response of the macaque electroretinogram: reduction by experimental glaucoma. Invest Ophthalmol Vis Sci. 1999;40:1124-36.

Submit your next manuscript to BioMed Central and we will help you at every step:

- We accept pre-submission inquiries

- Our selector tool helps you to find the most relevant journal

- We provide round the clock customer support

- Convenient online submission

- Thorough peer review

- Inclusion in PubMed and all major indexing services

- Maximum visibility for your research

Submit your manuscript at www.biomedcentral.com/submit
Biomed Central 